\title{
Shoreline Extraction and Change Detection using 1:5000 Scale Orthophoto Maps: A Case Study of Latvia-Riga
}

\author{
Bülent Bayram ${ }^{1}$, Inese Janpaule², Özgür Avşar ${ }^{3}$, Mustafa Oğurlu ${ }^{4}$, Salih \\ Bozkurt $^{5}$, Hatice Çatal Reis ${ }^{1}$, Dursun Zafer Seker, \\ ${ }^{1}$ Yildiz Technical University, Civil Eng'g Fac., Dept. of Geomatics Eng'g, 34220, ESENLER, ISTANBUL, TR \\ ${ }^{2}$ University of Latvia, Institute of Geodesy and Geoinformation, RIGA, LATVIA, LT \\ ${ }^{3}$ Istanbul Technical University, Civil Eng'g Fac., Dept. of Geomatics Eng'g, 34469, MASLAK, ISTANBUL, TR \\ ${ }^{4}$ GIS Department, Istanbul Water and Sewerage Administration, 34130, FATIH, ISTANBUL, TR \\ ${ }^{5}$ Undergraduate Student, Yildiz Technical University, Dept. of Geomatics Engineering, 34220, ESENLER, ISTANBUL, TR
}

\begin{abstract}
Coastal management requires rapid, up-to-date, and correct information. Thus, the determination of coastal movements and its directions has primary importance for coastal managers. For monitoring the change of shorelines, remote sensing data, very high resolution aerial images and orthophoto maps are utilized for detections of change on shorelines. It is possible to monitor coastal changes by extracting the coastline from orthophoto maps. Along the Baltic Sea and Riga Gulf, Latvian coastline length is $496 \mathrm{~km}$. It is rich of coastal resources and natural biodiversity. Around $120 \mathrm{~km}$ of coastline are affected by significant coastal changes caused by climate change, storms, erosion, human activities and other reasons and they must be monitored. In this study, an object-oriented approach has been proposed to detect shoreline and detect the changes by using 1:5000 scaled orthophoto maps of Riga-Latvia (3bands, R, G, and NIR) in the years of 2007 and 2013. As many of the authors have mentioned, object-oriented classification method can be more successful than the pixel-based methods especially for high resolution images to avoid mix-classification. In the presented study the eCognition object-oriented fuzzy image processing software has been used. The results were compared to the results derived from manual digitizing. Extracted and manually digitized shorelines have been divided in $5 \mathrm{~m}$ segments in $\mathrm{x}$ axis. The y coordinates of the new nodes were taken from the original ".dxf" file or computed by interpolation. Thus, the RMS errors of selected points were calculated.
\end{abstract}

Keywords: Shoreline extraction, object-oriented classification, image processing, change detection, orthophoto map

\section{Introduction}

Introduction

Since coastal zones include a wide variety of living and non-living resources, they are very complex ecosystems and indispensable socioeconomic environment (Raju et al., 2015). Scientific information is one of the main resources of coastal managers and planners to bring efficient and fulfilled solutions to preserve natural environmental resources (Houser et al., 2008). Coastal areas are under effect of various factors which are evolving these areas such as morphology and geology of coastal area, location, length and width of area, climatological factors, sedimentation, rivers around coastal area, waves, and effects of tide (Albert and Jorge, 1998).

There are several factors which make the monitoring of coastal changes essential for coastal managers same as defining of correlation between dune morphology, bathymetry and land (Houser et al., 2008). 
Remote sensing and geographical information system (GIS) have been used widely in costal monitoring studies in recent twenty years (Kuleli et al., 2011; Maiti and Bhattacharya, 2009; Yamano et al., 2006; Siddiqui and Maajid, 2004; Ryu et al., 2002). Monitoring of shoreline changes is very important for planning, defining of hazard zones, and predicting of erosion and sediment transportation and being aware of coastal morph dynamics (Bayram et al., 2013; Ford 2013; Kumar et al., 2010). Periodic monitoring of shorelines and defining of is crucial (Karsli et al, 2011). Despise natural effects human interactions with shorelines and their results have to be taken into consideration. Satellite data and aerial photographs have been commonly used in many studies based on monitoring of detection of shoreline changes (Kankara et al., 2015). To extract shorelines several pixel-based approaches have been proposed (Ozturk and Sesli, 2015). However, many studies suggested object-oriented suggestions to accomplish difficulties of pixelbased methods (Kassouk et al., 2014).

The aim of this study is to extract the shoreline and define shoreline changes of Riga Gulf by using object-oriented fuzzy classification technique. Shorelines have been extracted using orthophoto maps in the years of 2007 and
2013 and in the scale of 1:5000 which includes $\mathrm{R}, \mathrm{G}$ and NIR bands.

\section{Study Area}

Along the Baltic Sea and Riga Gulf, Latvian coastline length is $496 \mathrm{~km}$. It is rich of coastal resources and natural biodiversity. All sanddunes of Baltic Sea and Riga Gulf coastline are being protected by protective zone which is at least 300 meters wide. Around $120 \mathrm{~km}$ of coastline are affected by significant coastal changes caused by climate change, wind, storms, erosion, human activities and other reasons. Coast abrasion occurs in some parts of coastline, in some parts - accumulation of sand and in some parts - dynamic balance, which is simultaneous abrasion and accumulation. In this study 1:5000 scaled orthophoto maps of Bullusala and Bull,upe in Riga-Latvia (3 bands; R, G, and NIR) in years of 2007 and 2013 were used. Bullusala is an island located in the South part of the Riga Gulf, between entry of river Daugava in the East, entry of river Lielupe in the West and river Bullupe in the South. Island has been formed in the 18th century during the floods of Lielupe. Also at present ambient rivers influence the coastline changes of Bullusala and its surroundings. The $13 \mathrm{~km}$ part of Riga shoreline has been extracted and temporal analysis examined (Fig 1).
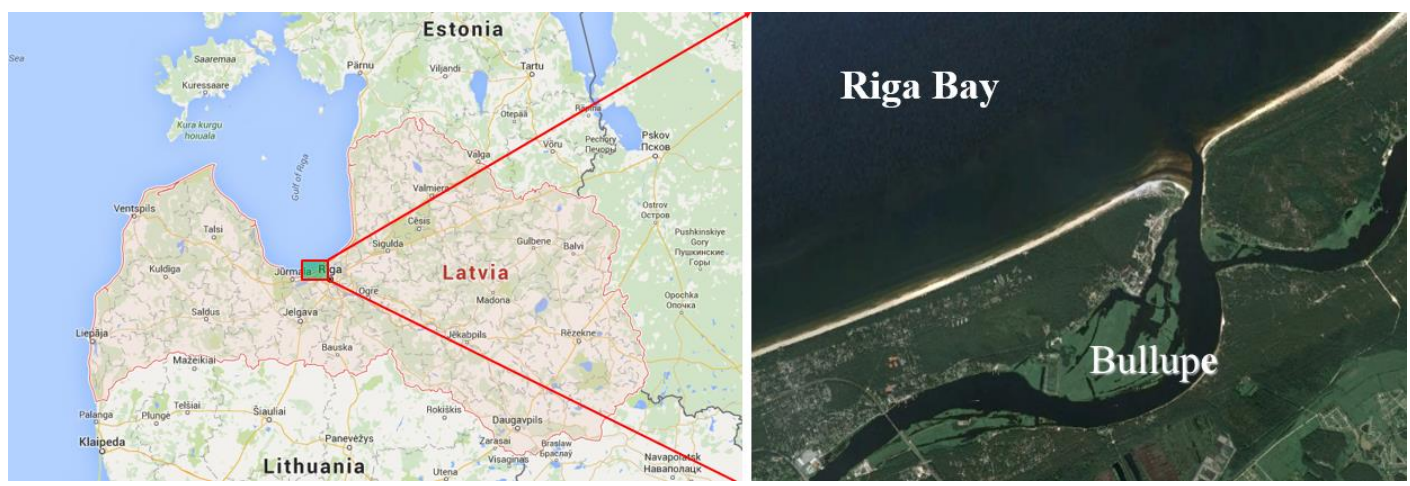

Fig 1. Study area

\section{Material and Method}

Object-oriented classification has been realized by eCognition Professional 5 software (Definiens, 2006). The software requires interactively setting of three parameters which are scale, colour and form to create homogenous segments to realize classification. The detailed information can be found in (Baatz and Schäpe 2000). The reason of using NIR band is appearing of water areas darker in the image. This physical behaviour of water bodies at NIR wavelengths make the extraction process easier (Raju et al., 2015; Lillesand and Kiefer, 1999). 
In the first step of the study, segmentation has been done. For all processed data:

- $\quad$ scale factor was set as 1000

- $\quad$ colour parameter was set as 0,9

- $\quad$ compactness parameter was set as 0,8

Sample segmentation result has been given in Fig 2.

Since fuzzy based object-oriented classification was used in this study, the fuzzy membership function and its thresholds must be defined primarily to perform the classification. Only two classes were assigned which are "water body", and "land". For object-based classification "Ratio" object based feature has been used which has been provided by used software. "The ratio of layer $\mathrm{k}$ reflects the amount that layer $\mathrm{k}$ contributes to the total brightness" (Definiens, 2006).

The parameters of object based feature are: wkB : brightness weight of layer $\mathrm{k}$

$\mathrm{ck}(\mathrm{v})$ : mean intensity of layer $\mathrm{k}$ of an image object $\mathrm{V}$

$\mathrm{c}(\mathrm{v})$ : brightness

and the formula:

$$
\begin{aligned}
& \text { If } \mathrm{wkB}=1 \text { and } \mathrm{c}(\mathrm{v}) \neq 0 \text { then } \\
& \text { (1) } \\
& \frac{c_{k}(v)}{c(v)}
\end{aligned}
$$

As fuzzy membership function "About range" membership function has been used (Fig 3).

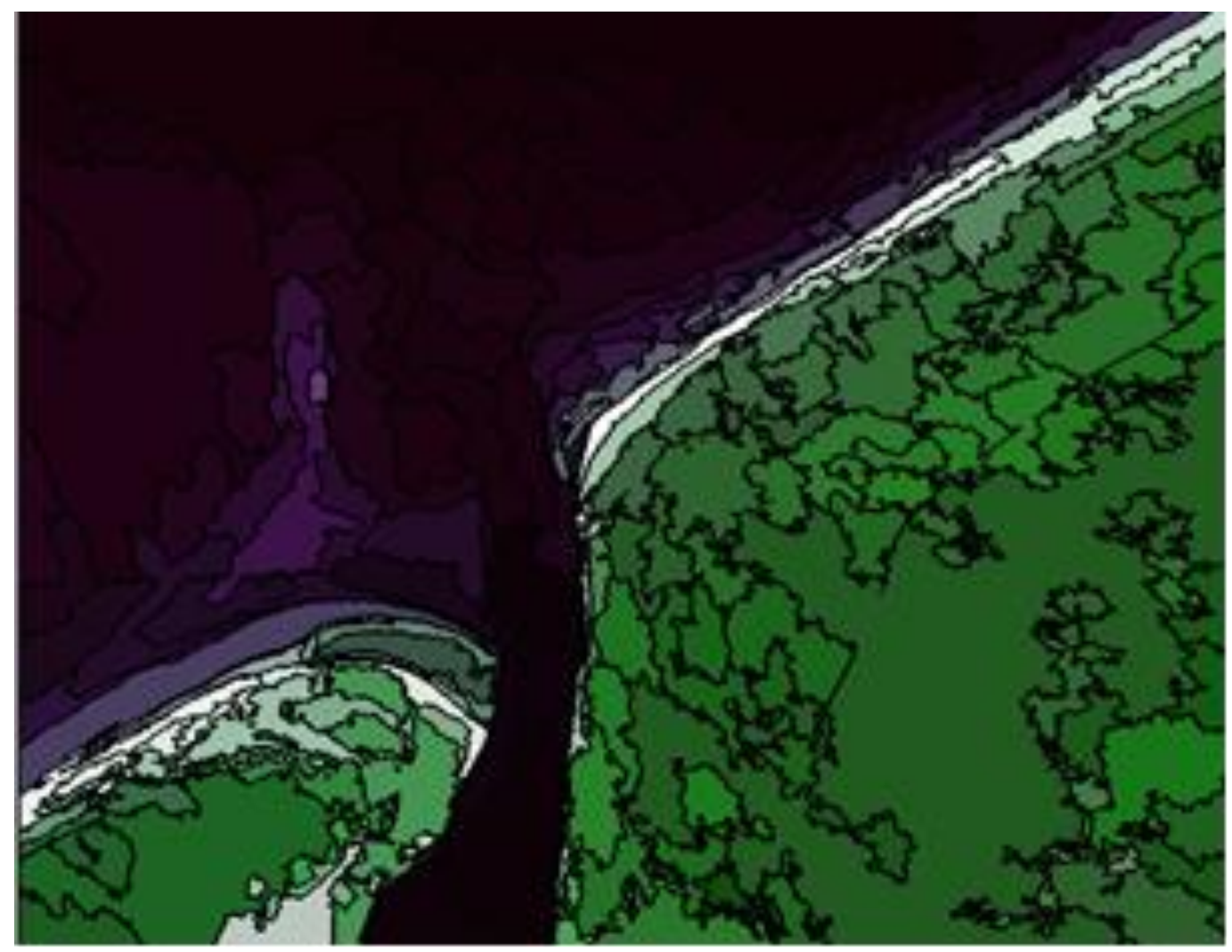

Fig 2. Segmentation results 


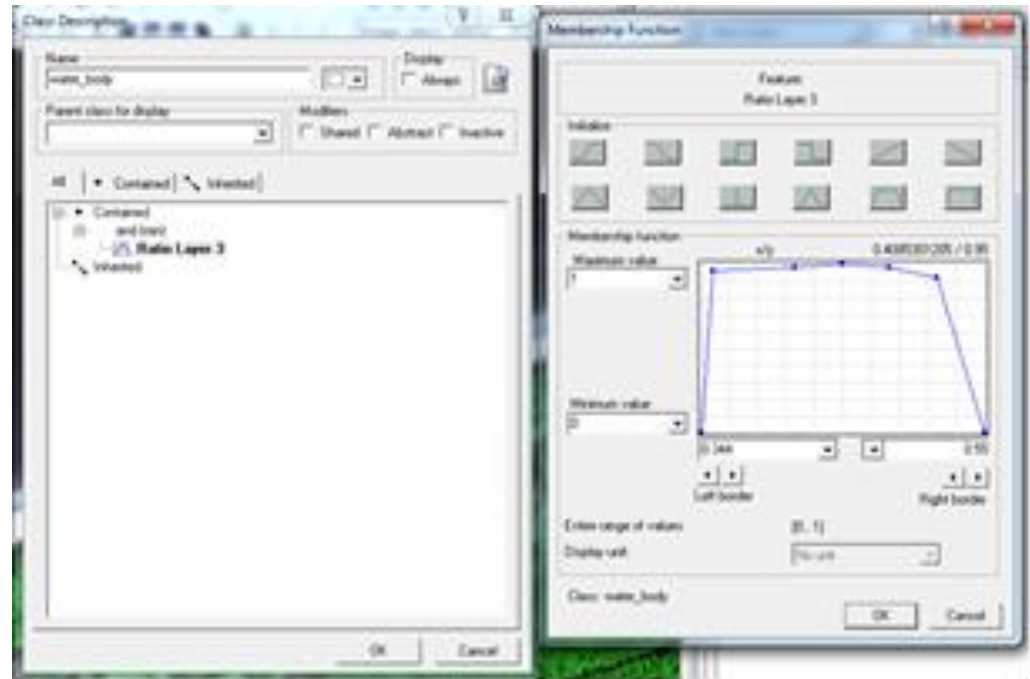

Fig 3. Fuzzy membership function

The classification results have been given in Fig 4-a,b. After segmenting of water body and land classes, shorelines have been obtained by raster to vector conversion. Extracted shorelines (Fig 5-a,b) have been compared with manual digitizing results (Fig 6-a,b) for accuracy assessment.

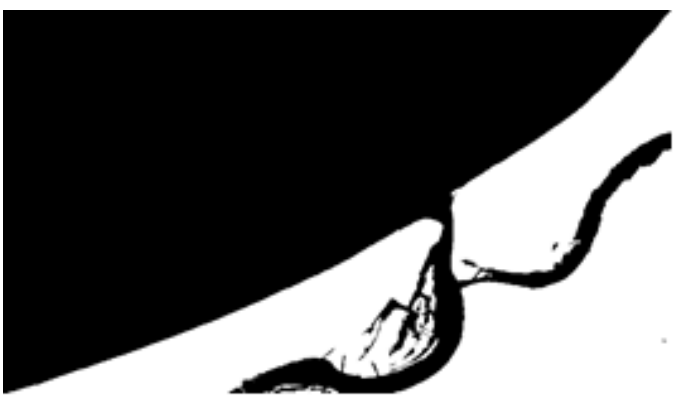

Fig 4-a. Classification results of 2007

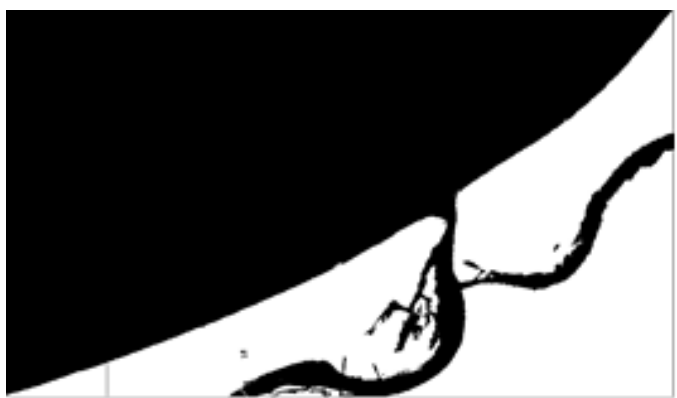

Fig 4-b. Classification results of 2013

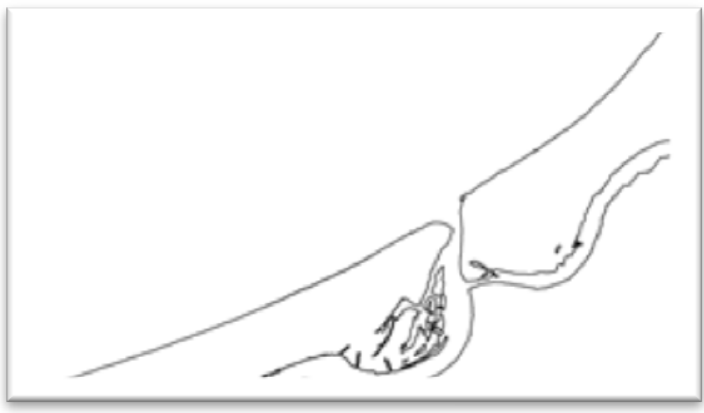

Fig 5-a. Extracted shoreline of 2007

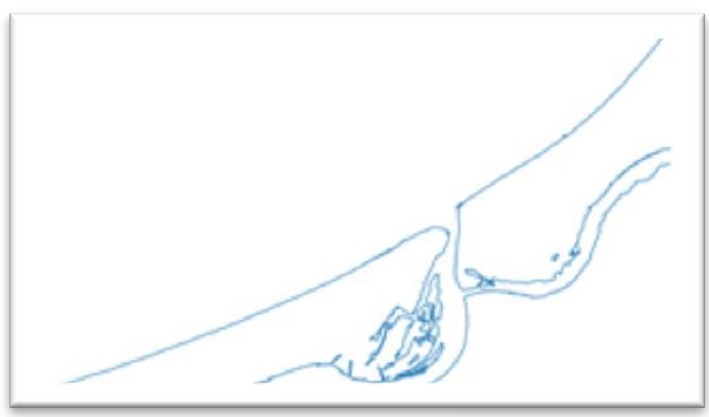

Fig 5-b. Extracted shoreline of 2013

An algorithm has been developed by using MATLAB for accuracy assessment and analysing of temporal changes between 2007 and 2013. The results between object-oriented shoreline extraction and manual digitizing have been compared for both 2007 and 2013 . According to algorithm, shoreline extraction results have been taken as reference data. The 
master and slave files divided by $5 \mathrm{~m}$ segments in $\mathrm{x}$ axis. The $\mathrm{y}$ coordinates of the new nodes were taken from the original ".dxf" file or computed by interpolation if necessary. The differences between y coordinates of reference and slave files and its root mean square errors have been computed.

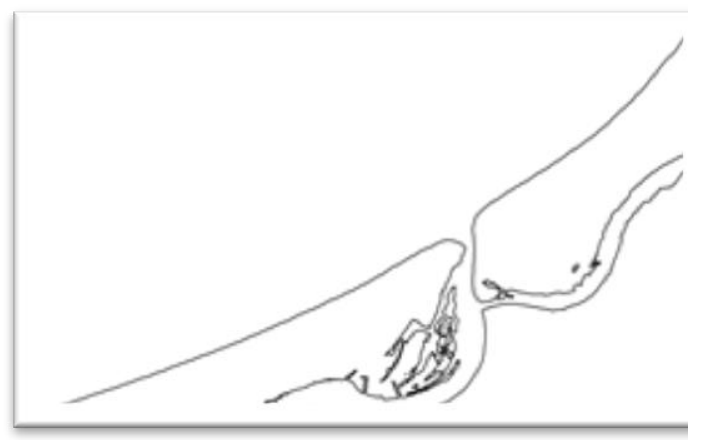

Fig 6-a. Manually digitized shoreline of 2007

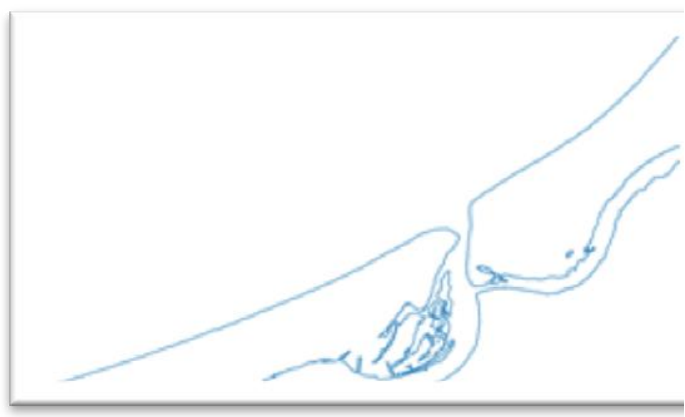

Fig 6-b. Manually digitized shoreline of 2013

\section{Results and Discussions}

The 13 part of Riga- Bullupe shorelines under treat of abrasion have been extracted by objectoriented fuzzy approach from orthophoto maps in years oh 2007 and 2013 and temporal changes have been monitored. Two main object classes have been created as "water" and "land" to extract shoreline. The segmentation results were converted into ".dxf" vector data format. The extraction results have been evaluated by manual digitizing results. The same method has been used both accuracy assessment and shoreline change analysis. Minimum, maximum, average differences between proposed method and manual digitizing for 2007 have been calculated as $0.00 \mathrm{~m}, 43.30 \mathrm{~m}$, $2.97 \mathrm{~m}$ respectively. The calculated standard deviation is $3.21 \mathrm{~m}$. Again, minimum, maximum, average differences between proposed method and manual digitizing for 2013 have been calculated as $0.00 \mathrm{~m}, 50.90 \mathrm{~m}$, $7.14 \mathrm{~m}$ respectively. The calculated standard deviation is $5.67 \mathrm{~m}$. It has been though that the maximum calculated differences for 2007 and 2013 have been occurred because of the human interpretation error. According to comparison of two extracted shorelines in years of 2007 and 2013, minimum, maximum, average differences have been calculated as $0.00 \mathrm{~m}, 98.0 \mathrm{~m}, 8.14 \mathrm{~m}$ respectively.

The calculations have been by using 2260 points along the shoreline. The $71 \%$ of differences were in $0-10 \mathrm{~m}$, the $23 \%$ of differences were in 11-20 m, $6 \%$ of differences were in 11-98 m between 2007 and 2013. As it can be seen in Fig 7, maximum changes are at the intersection location between Batlic Sea and Bullupe River. The effect of Bullupe River is should be taken into serious.

As a result, it has been seen that proposed object-oriented approach is relevant and methodology can be used efficiently similar areas to monitor temporal shoreline changes. Also, for determination and control of longshore sediment transport models to evaluate the simulation results the proposed coastline extraction method can be successfully used. Thus, the remote sensing technique can be fused with the sediment transport results.

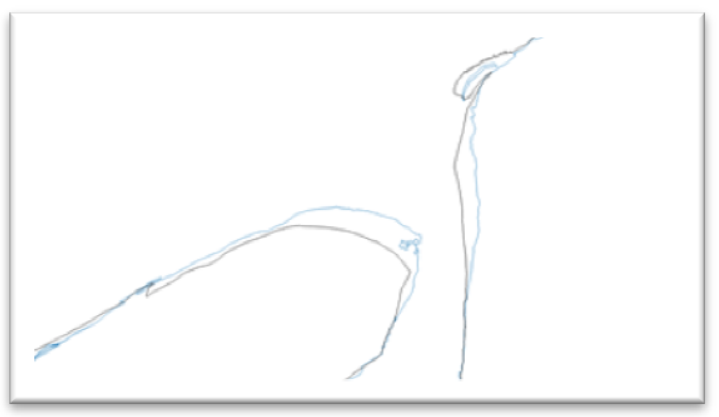

Fig 7. Maximum changes at Riga-Bullupe shoreline

\section{Acknowledgment}

The authors are thankful to Mr. Peteris Petersons (Latvian Geospatial Information Agency, Dept. of Geodesy and Cartography, Riga, Latvia) for providing orthopohoto maps. 


\section{References}

Albert, P., Jorge, G. 1998. Coastal changes in the Ebro delta: natural and human factors. Journal of Coastal Conservation, 4, 17-26.

Baatz, M., Schäpe, A. 2000. Multiresolution segmentation an optimization approach for high quality multi-scale image segmentation. In: Strobl, J., Blaschke, T., Griesebener, G. (Eds.), Angewandte Geographische Informationsverarbeitung XII. Beiträge zum AGIT-Symposium Salzburg 2000, Herbert Wichmann Verlag, Kahrlsruhe, pp. 12-23.

Bayram, B., Seker, D.Z., Acar, U., Yuksel, Y., Guner, H., Ar1, A., Cetin, I. 2013. An Integrated Approach to Temporal Monitoring of the Shoreline and Basin of Terkos Lake. Journal of Coastal Research, 29 (6), 1427-1435.

Definiens, Definiens Professional 5 Reference Book, Definiens AG, http://read.pudn.com/downloads112/sourcec ode/others/467350/eCognition5.0\%20Refer enceBook.pdf, (Accessed 05 April 2009).

Ford, M. 2013. Shoreline changes interpreted from multi-temporal aerial photographs and high resolution satellite images: Wotje Atoll, Marshall Islands. Remote Sensing of Environment, 135, 130-140.

Houser, C., Hapke, C., Hamilton, S. 2008. Controls on coastal dune morphology, shoreline erosion and barrier island response to extreme storms. Geomorphology, 100, 223-240.

Kankara, R.S., Selvan, S.C., Markose, V.J., Rajan, B., Arockiaraj, S. 2015. Estimation of long and short term shoreline changes along Andhra Pradesh coast using Remote Sensing and GIS techniques. Procedia Engineering, 116, 855 - 862.

Karsli, F., Guneroglu, A., Dihkan, M., 2011. Spatio-temporal shoreline changes along the southern Black Sea coastal zone. J. Appl. Remote Sens., 5 (1), 053545, doi/10.1117/1.3624520.

Kassouk, Z., Thouret, J.C., Gupta, A., Solikhin, A., Liew S.C. 2014. Object-oriented classification of a high-spatial resolution SPOT5 image for mapping geology and landforms of active volcanoes: Semeru case study, Indonesia. Geomorphology, 221, 1833.
Kuleli, T., Guneroglu, A., Karsli, F., Dihkan, M. 2011. Automatic detection of shoreline change on coastal Ramsar wetlands of Turkey. Ocean Engineering, 38, 1141-1149.

Kumara, A., Narayana, A.C., Jayappa, K.S. 2010. Shoreline changes and morphology of spits along southern Karnataka, west coast of India: A remote sensing and statisticsbased approach. Geomorphology, 120, 133152.

Lillesand, T.M., Kiefer, R.W. 1999. Remote sensing and image interpretation, 4th. Ed., John Wiley and Son, USA, pp. 122, 19, G70.4.L54.

Maiti, S., Bhattacharya, A.K., 2009. Shoreline change analysis and its application to prediction: a remote sensing and statistics based approach. Marine Geology, 257, 1123.

Ozturk, D., Sesli, A.F. 2015. Shoreline change analysis of the Kizilirmak Lagoon Series. Ocean \& Coastal Management, 118, 290308.

Raju, A., Dwarakish, G.S., Venkat, R. 2015. Automatic Shoreline Detection and Change Detection Analysis of Netravati-Gurpur Rivermouth Using Histogram Equalization and Adaptive Thresholding Techniques. Aquatic Procedia, 4, $563-570$.

Ryu, J.H., Won, J.S., Min, K.D. 2002. Waterline extraction from Landsat TM data in a tidal flat: a case study in Gosmo Bay, Korea. Remote Sensing of Environment, 83, 442-456.

Siddiqui, M.N., Maajid, S. 2004. Monitoring of geomorphological changes for planning reclamation work in coastal area of Karachi, Pakistan. Advanced Space Research, 33, 1200-1205.

Yamano, H., Shimazaki, H., Matsunaga, T., Ishoda, A., McClennen, C., Yokoki, H., Fujita, K., Osawa, Y., Kayanne, H. 2006. Evaluation of various satellite sensors for waterline extraction in a coral reef environment: Majuro Atoll, Marshall Islands. Geomorphology, 82, 398-411. 